Abstracta Iranica

Revue bibliographique pour le domaine irano-aryen

Volume 42-43 | 2021

Comptes rendus des publications de 2019-2020

\title{
Thomas T. Allsen. The Steppe and the Sea. Pearls in the Mongol Empire
}

\section{Denise Aigle}

\section{OpenEdition}

10 Journals

\section{Édition électronique}

URL : https://journals.openedition.org/abstractairanica/51858

DOI : 10.4000/abstractairanica.51858

ISSN : 1961-960X

Éditeur :

CNRS (UMR 7528 Mondes iraniens et indiens), Éditions de l'IFRI

Référence électronique

Denise Aigle, "Thomas T. Allsen. The Steppe and the Sea. Pearls in the Mongol Empire », Abstracta Iranica [En ligne], Volume 42-43 | 2021, document 2, mis en ligne le 30 décembre 2020, consulté le 14 décembre 2022. URL : http://journals.openedition.org/abstractairanica/51858; DOI : https://doi.org/ 10.4000/abstractairanica.51858

Ce document a été généré automatiquement le 14 décembre 2022.

Tous droits réservés 


\title{
Thomas T. Allsen. The Steppe and the Sea. Pearls in the Mongol Empire
}

\author{
Denise Aigle
}

\section{RÉFÉRENCE}

Thomas T. Allsen. The Steppe and the Sea. Pearls in the Mongol Empire. Philadelphia:

University of Pennsylvania Press, 2019, 240 p., ISBN 978-0812251173

1 L'ouvrage de Thomas Allsen sur les perles vise à étudier leur usage dans l'Empire mongol. Il s'agit malheureusement du dernier livre que T. Allsen, cet éminent spécialiste des Mongols, nous donne à lire car il est décédé en février 2019, peu avant la publication de The Steppe and the Sea. Pearls in the Mongol Empire. Ce livre s'inscrit en continuité avec les recherches antérieures de l'A. sur les interactions politiques, culturelles et commerciales que l'Empire mongol.

2 L'A. s'intéresse à la nécessité qu'avaient les qa'an mongols d'accumuler massivement des biens de luxe, comme les perles. Elles participaient à des échanges dynamiques à travers tout "l'ulus" mongol, et même au-delà de ses frontières. Après avoir étudié comment l'acquisition des textiles pour confectionner les vêtements de la famille impériale gengiskhanide avait été un facteur central de la culture politique des Mongols (Th. Allsen, Commodity and Exchange in the Mongol Empire: A Cultural History of Islamic Textiles, Cambridge, Cambridge University Press, 1997, voir recension D. Aigle, dans Abstracta Iranica, vol. 24, 2003), l'A. utilise ici les perles comme une nouvelle fenêtre pour aborder ce champ de la culture mongole. Il s'intéresse au rôle des réseaux de communication maritimes, créés par les marchands indiens et les grands négociants internationaux musulmans, que les Mongols ont été capables d'utiliser pour se procurer les perles. Étant donné la taille immense de l'empire, on peut se demander comment les Mongols ont pu acquérir tant de perles sur de si longues distances. La situation était différente selon les régions. Au nord, les Gengiskhanides ont revitalisé les anciennes relations commerciales entre les peuples de la forêt et ceux de la 
toundra; dans la zone steppique, ils n'avaient en effet pas besoin d'intermédiaires et de conseillers. Dans les zones agricoles, au sud, ils ont attiré dans leur orbite les marchands internationaux afin d'identifier où se trouvaient les ressources en perles. L'extension de l'influence des Mongols dans les zones maritimes constituait un nouveau départ pour ce peuple nomade, mais aussi un nouveau défi. La tentative des Mongols d'imposer un contrôle administratif direct sur l'Asie du Sud-Est, et d'imposer leur domination navale a été ponctuée de défaites. Leur succès n'a été possible que grâce à la possession des côtes chinoises, ce qui a mis à leur disposition les ressources maritimes requises. Les Mongols sont parvenus à acquérir la technologie requise pour construire des navires. Ils ont également réussi à avoir accès aux traités de navigation permettant de parcourir les mers.

3 L'ouvrage est divisé en deux grandes parties. Dans la première («From the sea to the steppe ", constituée de huit courts chapitres, p. 11-85), l'A. étudie l'importance des perles dans la culture politique mongole. L'usage des perles dans les portraits des empereurs et ceux de leurs épouses montre qu'elles n'avaient pas seulement une valeur décorative, elles étaient le symbole de leur pouvoir. Selon l'A., les hommes ont toujours été fascinés par les perles en raison de leur relation avec leurs origines mystérieuses: "The emergence of a beautiful, lustruous object from an unattractive sea creature seems a most unlikely phenomenon» (p.11). Les hommes ont donné de la valeur aux objets qui ont une signification symbolique pour rehausser leur statut social et politique. L'A. parle de «class objects » (p. 13). Il décrit les régions maritimes riches en perles comme par exemple le golfe Persique bien connu pour ses "pearls beds" (ma'dan-i marwārīd), la côte du Fārs, l'île de Qays près d'Hormuz, Kharak. Aden et la Mer rouge étaient aussi des zones où l'on pêchait des perles (p. 16).

4 L'A. étudie les différentes modalités qui permettaient d'acquérir des perles: butin, relations tributaires, commerce, cadeaux, etc. Le premier grand butin en perles eut lieu en 1215, lorsque les Mongols ont occupé Zhongdu et se sont emparés du trésor du palais des Jin. Un peu plus tard, un butin immense et sans précédent eut lieu à Bagdad en 1259. Hülegü aurait dit en le voyant : " precious stones and pearls were like the sand on the sea » (p. 23). À côté des trésors royaux, les institutions ecclésiastiques notamment orthodoxes étaient une autre source d'approvisionnement en perles. Le tribut prélevé sur les États et les principautés soumises était une seconde source pour acquérir des perles. Qubila imposa par exemple un tribut en perles sur Java (p. 14). L'A. étudie l'usage des perles comme présents dans les relations diplomatiques. L'Ilkhan Abū Sa î̀ envoya des perles à la cour des Yünan pour réaffirmer son alliance avec le qa'an de Chine (p. 25). Le commerce constituait une autre source importante pour se procurer des perles sur de longues distances. Le commerce des perles était très ancien, mais au début du Moyen Âge, les Chinois et les Indiens connaissaient très bien les ressources en perles dans toute la zone des mers du sud. Par la suite, les musulmans et les marchands européens s'intéressèrent eux aussi au commerce des perles. Le commerce des perles était aussi une source de revenus importante pour les Mongols qui imposaient des taxes sur les transactions commerciales, le tamgha. À l'origine, il était versé en numéraire, mais il pouvait être remis en nature, notamment en perles (p. 32). L'A. met en lumière un aspect original de la symbolique des perles chez les Mongols. Elles sont associées à la virilité et à la fertilité. On retrouve les perles dans le mythe d'origine des Mongols. Selon l'Histoire secrète des Mongols, relatée sous une forme islamisée dans les sources persanes, Alan Qo'a aurait donné naissance au qa'an sans avoir été fécondée par un être humain, comme Marie pour Jésus. "The [Creator] perfected the pure womb of Alan 
Qo'a, brought forth the shell of the pearl of his noble birth of Chinggis Qan and created in this true essence from pure light » (p. 70). Alors que les peuples turks nomades et les Iraniens sédentaires des oasis considéraient la couleur blanche et les perles comme des sources de bonne fortune, seuls les Gengiskhanides en ont fait un élément intégral de leur idéologie impériale.

Dans la seconde partie ("Comparisons and influence», p. 89-166) de son livre, l'A. montre que les Mongols manifestaient un grand intérêt pour les encyclopédies, en particulier les Ilkhanides. Le plus ancien traité de ce type est The Treasure Book of the Ilhkhans de Nāṣir al-Dīn Ṭūsī compilé dans les années 1260 pour Hülegü. Cet ouvrage décrit les métaux, les minéraux et les pierres précieuses sur la base du Book of Precious Stones de Bīrūnī. D'autres ouvrages de ce type furent rédigés pour les Ilkhans (p. 100-102) et même pour les Yüan. Depuis l'Antiquité, des pouvoirs ésotériques et magiques étaient attribués aux perles. On considérait qu'elles pouvaient avoir des influences bénéfiques pour ceux qui en possédaient (p. 100-112). À ce titre, les marchands détenaient un pouvoir certain car ils étaient capables d'apporter aux Mongols des perles, en provenance de contrées lointaines. Dans certains cas, ils pouvaient même faire monter les prix (p. 142-153). Cet attrait pour les perles a conduit à cultiver les perles, une pratique qui remonte déjà au $\mathrm{IX}^{\mathrm{e}}$ siècle en Chine. On a également fabriqué des fausses perles et des artefacts (p. 113-123).

L'A. témoigne dans ce livre de sa très grande érudition, comme dans toutes ses autres publications. Il analyse un grand nombre de sources qui lui permettent de retracer la manière de circuler des perles en Asie intérieure et dans la steppe sur la longue durée. On peut considérer ce mouvement comme une sorte de processus de "southernization", avec la diffusion des technologies en relation avec les perles (pêche, perçage, utilisation sur les vêtements et les objets décoratifs) depuis le littoral de l'océan Indien vers les zones nordiques de la steppe. La cour gengiskhanide attirait marchands et marchandises de tout le «Old World» (p. 168) car l'empire créa un espace qui a facilité le commerce sur de longues distances. À un niveau encore plus fondamental, la formation d'un si vaste imperium nomade nécessitait aussi de redistribuer des biens, ce qui a conduit à créer une nouvelle forme de consommation à un niveau continental. On peut même parler d'une sorte de «mondialisation avant la lettre » à l'échelle de toute l'Eurasie médiévale.

\section{AUTEURS}

\section{DENISE AIGLE}

CNRS, Orient et Méditerranée, Paris 